https://doi.org/10.15690/vsp.v20i6S.2363

\author{
Н.Ю. Каширская ${ }^{1,2}$, Н.В. Петрова ${ }^{1}$, Р.А. Зинченко ${ }^{1,3}$ \\ 1 Медико-генетический научный центр имени академика Н.П. Бочкова, Москва, Российская Федерация \\ 2 Московский областной научно-исследовательский клинический институт (МОНИКИ) \\ им. М.Ф. Владимирского, Москва, Российская Федерация \\ 3 Национальный научно-исследовательский институт общественного здоровья имени Н.А. Семашко, \\ Москва, Российская Федерация
}

\title{
Клиническая эффективность
}

и безопасность комбинированного препарата ивакафтор/лумакафтор у пациентов с муковисцидозом: обзор международных исследований

\section{Контактная информация:}

Каширская Наталия Юрьевна, доктор медицинских наук, профессор, главный научный сотрудник лаборатории генетической эпидемиологии ФГБНУ “Медико-генетический научный центр имени академика Н.П. Бочкова", профессор кафедры педиатрии факультета усовершенствования врачей Московского областного научно-исследовательского клинического института им. М.Ф. Владимирского

Адрес: 115522, Москва, ул. Москворечье, д. 1, тел.: +7 (499) 320-60-90, e-mail: kashirskayanj@mail.ru

Статья поступила: 10.09.2021, принята к печати: 17.12 .2021

Муковисцидоз - аутосомно-рецессивное заболевание, вызванное нарушением структуры гена трансмембранного регулятора проводимости муковисцидоза (CFTR), характеризующееся тяжелым течением и неблагоприятным прогнозом при отсутствии или неоптимальном лечении. Одобрение для клинического применения в 2012 г. в США препаратов патогенетической терапии - модуляторов белка CFTR (потенциатор и корректоры) снизило летальность, связанную с этим заболеванием. В статье представлен обзор исследований клинической эффективности и безопасности комбинированного препарата ивакафтор плюс лумакафтор (Ива/Лум) - первого лицензированного препарата - модулятора CFTR для пациентов-гомозигот по варианту F508del. Показано, что Ива/Лум повышает функцию легких, снижает количество обострений бронхолегочного процесса, в том числе требующих введения антибиотиков и госпитализации, частично восстанавливает экзокринную функцию поджелудочной железы, увеличивает массу тела и массо-ростовой индекс, повышает качество жизни, что позволяет говорить о его благоприятном влиянии на течение и прогноз муковисцидоза. Отмечено также, что раннее начало применения препарата (с двухлетнего возраста) положительно влияет на прогноз заболевания, увеличивая продолжительность жизни и улучшая ее качество. Ключевые слова: муковисцидоз, патогенетическая терапия, модуляторы CFTR, ивакафтор, лумакафтор

Для цитирования: Каширская Н.Ю., Петрова Н.В., Зинченко Р.А. Клиническая эффективность и безопасность комбинированного препарата ивакафтор/лумакафтор у пациентов с муковисцидозом: обзор международных исследований. Вопросы современной педиатрии. 2021;20(6S):558-566. doi: 10.15690/vsp.v20i6S.2363

\section{ВВЕДЕНИЕ}

Муковисцидоз (кистозный фиброз) - частое наследственное аутосомно-рецессивное моногенное потенциально летальное заболевание, характеризующееся поражением всех экзокринных желез, что определяет вовлечение в патологический процесс легких и верхних отделов респираторного тракта, поджелудочной железы, кишечника, потовых желез, гепатобилиарной и репродуктивной систем [1]. Патогенез заболевания обусловлен нарушением транспорта ионов хлора на уровне клетки. Центральную роль в транспорте ионов хлора в эпителиальных клетках экзокринных желез играет белок трансмембранный регулятор проводимости муковисцидоза - CFTR (англ. cystic fibrosis transmembrane conductance regulator). Являясь трансмембранным белком, располагающимся на поверхности большинства эпителиальных клеток, функционирует как циклический аденозинмонофосфат (цАМФ)-зависимый хлорный канал, который способствует пассивному перемещению ионов хлора через поверхностные мембраны эпителиальных клеток в соответствии с градиентами концентрации [1]. CFTR также участвует в регуляции ряда ионных каналов и мембранного транспорта [2]. Принимая участие в транспорте солей и воды в легочном эпителии [1], а также в диффузии карбоксил-иона, CFTR регулирует тем самым рН внутри и снаружи клетки [1]. Велика роль CFTR в осуществлении секреции жидкости железами подслизистой оболочки, располагающейся под поверхностным эпителием дыхательных путей. На апикальных мембранах клеток поверхностного эпителия CFTR осуществляет абсорбцию ионов хлора $\left(\mathrm{Cl}^{-}\right)$вслед за абсорбцией натрия $\left(\mathrm{Na}^{+}\right)$, происходящей через натриевые каналы (ENaC) [1]. Считается, что баланс между этими двумя транспортными функциями CFTR необходим для поддержания оптимального объема поверхностной жидкости дыхательных путей для обеспечения цилиарного клиренса от слизи и бактерий [1]. При 
муковисцидозе происходит нарушение баланса между секрецией жидкости и абсорбцией ионов, в результате сокращается объем поверхностной жидкости, что приводит к увеличению вязкости жидкого секрета и неэффективности бактериального клиренса $[1,3,4]$. Кроме того, канал CFTR участвует в регуляции транспорта ионов $\mathrm{K}^{+}$и $\mathrm{Ca}^{2+}$ как в тканях легких, так и тканях органов желудочно-кишечного тракта [1, 3].

У пациентов с муковисцидозом снижение функции CFTR обусловлено повреждением одноименного гена, локализованного на длинном плече хромосомы 7 (7q31.1) [1]. Клиническая картина заболевания развивается при наличии патогенных нуклеотидных вариантов на обоих аллелях гена - т.н. биаллельности [1]. Описано (база CFTR1) более 2100 вариантов нуклеотидной последовательности гена CFTR [5]. В зависимости от влияния на количество и функцию канала CFTR выделяют 6 основных классов патогенных вариантов. Варианты классов I-III приводят к значительному снижению или полному прекращению синтеза белка либо к нарушению стабильности белка, как в случае с классом VI, что определяет выраженную клиническую картину заболевания со снижением экзокринной функции поджелудочной железы. При вариантах классов IV-V, как правило, функция поджелудочной железы не нарушается, а клиническая картина муковисцидоза определяется в первую очередь поражением легких [6]. Описание механизмов, приводящих к нарушению функции белка CFTR, и распространенность основных классов вариантов гена CFTR у пациентов с муковисцидозом представлены в таблице [7-9].

Большинство вариантов гена CFTR приводят к нарушению функции хлорного канала одноименного белка посредством нескольких механизмов. Так, наиболее распространенный вариант F508del (c.1521_1523delCTT, p.Phe508del) нарушает процессинг как вариант класса II, а активацию хлорного канала - как вариант класса III (gating-дефект). В расширенной классификации, предложенной G. Veit и соавт. [11], сделана попытка учесть комбинированные проявления мутантных аллелей гена CFTR на молекулярном и клеточном уровнях. Эта расширенная классификация включает 31 класс вариантов: основные классы I, II, III/IV, V и VI, а также их 26 комбинаций. Для простоты варианты классов III и IV, представляющие собой функциональные (gating и проводящие соответственно) варианты гена CFTR, объединяются в один класс (III/IV). Согласно расширенной классификации, вариант G551D, как и раньше, отнесен к класcy III, тогда как вариант F508del - к классу II-III-VI, W1282X - к классу I-II-III-VI, P67L - к классу II-III, $\mathrm{R} 117 \mathrm{H}$ - к классу II-III/IV, т.е. такая классификация отражает сложные дефекты в биологии мутантных белков CFTR. Исследование экспрессии мутантных белков CFTR в эпителии щитовидной железы крысы Фишера, проведенное компанией Vertex Pharmaceuticals, продемонстрировало, что 24 из 54 миссенс-вариантов приводят одновременно и к нарушению процессинга (класс II), и к gating-дефекту (класс III). Считается, что такие комбинации изменений гена CFTR, приводящих к нарушению синтеза/структуры белка, необходимо учитывать при разработке новых лекарственных средств и внедрении их в практику [11].

Патогенный вариант F508del ассоциирован с тяжелым течением заболевания, ранней манифестацией симптомов, ранним поражением бронхолегочной системы, нарушением функции поджелудочной железы и, как результат, высокой летальностью в детском возрасте. Особенно тяжело заболевание протекает у пациентов, гомозиготных по F508del, когда оба аллеля гена CFTR несут данный патогенный вариант. В странах Европейского союза в целом около 50\% пациентов гомозиготны по аллелю F508del [12]. По данным российского регистра больных муковисцидозом за 2019 г., доля гомозиготных генотипов составляет 30\%, а хотя бы в одном аллеле данный вариант имеют более 75\% пациентов [10].

Стандартную терапию муковисцидоза в Российской Федерации составляют кинезиотерапевтические мето-

Nataliya Yu. Kashirskaya ${ }^{1,2}$, Nika V. Petrova ${ }^{1}$, Rena A. Zinchenko ${ }^{1,3}$

${ }^{1}$ Research Centre for Medical Genetics, Moscow, Russian Federation

2 Moscow Regional Research and Clinical Institute (MONIKI), Moscow, Russian Federation

3 N.A. Semashko National Research Institute of Public Health, Moscow, Russian Federation

\section{Clinical Efficacy and Safety of Ivacaftor/Lumacaftor Combination in Patients with Cystic Fibrosis: International Studies Review}

Cystic fibrosis is an autosomal recessive disease caused by structure abnormalities in the cystic fibrosis transmembrane conductance regulator (CFTR) gene. It is characterized by severe course and poor prognosis without or with insufficient treatment. Approval of pathogenetic therapy medications, CFTR modulators (potentiators and correctors), for clinical use in 2012 in the United States has reduced mortality from this disease. This article provides the overview of studies on clinical efficacy and safety of ivacaftor/lumacaftor combination (Iva/Lum) - the first licensed CFTR modulator medication for homozygous patients with F508del variant. It was shown that Iva/Lum increases lung function, reduce the number of pulmonary exacerbations (including those that require antibiotics and hospitalization), partially restores pancreas exocrine function, increases body weight and mass growth index, and improves quality of life. It allows considering it as favorable effect on the course and prognosis of cystic fibrosis. It was also noted that the early onset of the drug administration (from the age of two) positively affects the prognosis of the disease, increasing life expectancy and improving quality of life.

Keywords: cystic fibrosis, pathogenetic therapy, CFTR modulators, ivacaftor, lumacaftor

For citation: Kashirskaya Nataliya Yu., Petrova Nika V., Zinchenko Rena A. Clinical Efficacy and Safety of Ivacaftor/Lumacaftor Combination in Patients with Cystic Fibrosis: International Studies Review. Voprosy sovremennoi pediatrii - Current Pediatrics. 2021;20(6S):558-566. (In Russ). doi: 10.15690/vsp.v20i6S.2363 
Таблица. Классификация вариантов гена CFTR и их влияние на функцию одноименного белка Table. Classification of CFTR gene variants and their effect on the CFTR protein functions

\begin{tabular}{|c|c|c|c|c|c|c|c|}
\hline $\begin{array}{c}\text { Традиционная } \\
\text { классификация }\end{array}$ & \multicolumn{2}{|c|}{ Класс I } & Класс II & Класс III & Класс IV & Класс V & Класс VI \\
\hline $\begin{array}{c}\text { Новая } \\
\text { классификация }\end{array}$ & Класс I a & Класс I b & Класс II & Класс III & Класс IV & Класс V & Класс VI \\
\hline \multirow{2}{*}{ Дефект CFTR } & \multicolumn{2}{|c|}{ Нарушение синтеза белка } & \multirow{2}{*}{$\begin{array}{c}\text { Нарушение } \\
\text { процес- } \\
\text { синга или } \\
\text { транспорта }\end{array}$} & \multirow{2}{*}{$\begin{array}{c}\text { Нарушение } \\
\text { регуляции } \\
\text { (gating- } \\
\text { дефект) }\end{array}$} & \multirow{2}{*}{$\begin{array}{c}\text { Снижение } \\
\text { проводи- } \\
\text { мости }\end{array}$} & \multirow{2}{*}{$\begin{array}{c}\text { Снижение коли- } \\
\text { чества нормаль- } \\
\text { ных молекул } \\
\text { белка или РНк }\end{array}$} & \multirow{2}{*}{$\begin{array}{c}\text { Снижение } \\
\text { стабиль- } \\
\text { ности про- } \\
\text { теина }\end{array}$} \\
\hline & Нет мРНК & Нет белка & & & & & \\
\hline Примеры вариантов & $\begin{array}{c}621+1 \mathrm{C}>\mathrm{T}^{*} \\
\text { CFTRdele } 2,3^{*} \\
\text { 1717-G>A } \\
2143 \text { delT* } \\
\text { 2184insA* } \\
\text { 1677delTA* } \\
\text { 394delTT* } \\
\text { 3821delT* } \\
\text { 1367del5* } \\
\text { 3944delGT* } \\
\text { 712-1G }>\mathrm{T}^{*} \\
\text { 621+1G }>\mathrm{T}^{*} \\
\text { 1898+1G }>\text { C* } \\
\text { 1898+1G }>\mathrm{A}^{*} \\
\text { CFTRdup6b-10* }\end{array}$ & $\begin{array}{c}\text { G542X* } \\
\text { W1282X* } \\
\text { R553X* } \\
\text { S1196X* } \\
\text { W1310X* } \\
\text { R1162X* } \\
\text { R785X* } \\
\text { S466X* }\end{array}$ & $\begin{array}{c}\text { F508del* } \\
\text { N1303K* } \\
\text { I507del } \\
\text { S549I } \\
\text { S549R } \\
\text { R1066C* } \\
\text { G85E* } \\
\text { E92K* } \\
\text { W1282R* }\end{array}$ & $\begin{array}{c}\text { G178R } \\
\text { G551D } \\
\text { R560T } \\
\text { G970R } \\
\text { G1244E } \\
\text { S1255P }\end{array}$ & $\begin{array}{c}\text { R117H } \\
\text { R334W* } \\
\text { R347P* } \\
\text { R1070W } \\
\text { D1152H } \\
\text { L138ins* }\end{array}$ & $\begin{array}{c}3272-26 A>G \\
3272-16 T>A^{*} \\
2789+5 G>A^{*} \\
3849+10 k b C>T^{*} \\
A 455 E \\
\text { IVS8(5T) } \\
1811+1,6 k b A>G \\
D 565 G\end{array}$ & $\begin{array}{l}\text { S1455X } \\
\text { c.120del123 } \\
\text { rF508del }\end{array}$ \\
\hline $\begin{array}{l}\text { Доля пациентов с хотя } \\
\text { бы одним вариантом, \% }\end{array}$ & \multicolumn{2}{|c|}{22} & 88 & 6 & 6 & 5 & 5 \\
\hline $\begin{array}{l}\text { Патогенетическая } \\
\text { терапия }\end{array}$ & Нет & $\begin{array}{c}\text { Восста- } \\
\text { новление } \\
\text { синтеза }\end{array}$ & $\begin{array}{c}\text { Восста- } \\
\text { новление } \\
\text { транспорта }\end{array}$ & $\begin{array}{c}\text { Восста- } \\
\text { новление } \\
\text { активности } \\
\text { канала }\end{array}$ & $\begin{array}{c}\text { Восста- } \\
\text { новление } \\
\text { активности } \\
\text { канала }\end{array}$ & $\begin{array}{c}\text { Исправление } \\
\text { сплайсинга }\end{array}$ & $\begin{array}{c}\text { Повышение } \\
\text { стабиль- } \\
\text { ности }\end{array}$ \\
\hline Клинический вариант & \multicolumn{4}{|c|}{ Более тяжелое течение } & \multicolumn{3}{|c|}{ Более легкое течение } \\
\hline
\end{tabular}

Примечание. <*> - частые (> 0,12\%) для Российской Федерации патогенные варианты гена CFTR, согласно российскому регистру больных муковисцидозом (по данным 2019 г.) [10].

Note. $\langle *\rangle$ - frequent $(>0,12 \%)$ for Russian Federation pathogenic variants in the CFTR gene according to the Russian register of patients with cystic fibrosis (according to 2019 y) [10].

дики, диета и широкий спектр симптоматических лекарственных препаратов, включая антибактериальные и противогрибковые, муколитики, бронходилататоры, ферменты поджелудочной железы для заместительной терапии, глюкокортикостероиды [13]. Следует подчеркнуть, что все эти препараты не влияют на собственно причину муковисцидоза - нарушение работы белка CFTR. Изучение патогенеза муковисцидоза способствовало разработке принципиально новых лекарственных средств, направленных на устранение дефектов в структуре белков CFTR для повышения их активности и восстановления ионного транспорта в клетке-мишени. В исследовании F. Van Goor и соавт. (2006) [14] впервые были изучены два новых класса препаратов, так называемых модуляторов: корректоры CFTR, увеличивающие количество функциональных копий белка CFTR, способного встроиться в клеточную мембрану, и потенциаторы CFTR, повышающие вероятность открытия канала белка CFTR, присутствующего на поверхности клетки. В настоящее время Управлением по санитарному надзору за качеством пищевых продуктов и медикаментов США (Food and Drug Administration; FDA) и Европейским агентством лекарственных средств (European Medicines Agency; EMA) разрешен к применению один потенциатор - ивакафтор, который уже с 2012 г. используется для монотерапии пациентов с определенными типами патологических вариантов, список которых постоянно обновляется в официальной инструкции [15], а также три корректора.
Последние применяют вместе с потенциатором в составе трех комбинированных препаратов: ивакафтор + лумакафтор, ивакафтор + тезакафтор и ивакафтор + тезакафтор + элексакафтор.

Первым модулятором, разрешенным для лечения гомозигот по F508del в гене CFTR, стал комбинированный препарат, включающий ивакафтор (VX-770) и лумакафтор (VX-809) [16]. Препарат был разработан компанией "Вертекс" (Vertex Pharmaceuticals) и одобрен FDA в июне 2015 г. Сочетанное назначение корректора и потенциатора было обосновано тем, что вариант F508del в гомозиготном состоянии одновременно приводит и к нарушению сборки и транспорта белка CFTR на поверхность клетки, а также к снижению его транспортной функции [17]. В результате было показано, что применение комбинированного препарата для патогенетической терапии муковисцидоза увеличивает выживаемость более чем на 23 года при его назначении с 6-летнего возраста [18]. В России комбинированный препарат ивакафтор/лумакафтор (Ива/Лум) был зарегистрирован в декабре 2020 г. На сегодняшний день в нашей стране отсутствуют какие-либо зарегистрированные аналоги этого лекарственного препарата, в том числе входящие в перечни лекарственных препаратов для медицинского применения. Это первая патогенетическая терапия для больных муковисцидозом. До настоящего времени клинические исследования препарата у российских пациентов с муковисцидозом не проводились. 
ОБЗОР ИССЛЕДОВАНИЙ ЭФФЕКТИВНОСТИ И БЕЗОПАСНОСТИ ИВАКАФТОРА/ЛУМАКАФТОРА ${ }^{1}$

Эффективность и безопасность комбинированного препарата Ива/Лум была оценена в клинических исследованиях с участием более 1100 пациентов в возрасте старше 12 лет [20, 21] и более 320 пациентов - младше 12 лет [22-24] с муковисцидозом, гомозиготных по патогенному варианту гена CFTR F508del, проведенных в исследовательских центрах США, Канады, Австралии, Великобритании, стран Европейского союза и других.

\section{Ивакафтор/лумакафтор у пациентов \\ с муковисцидозом в возрасте $\geqslant 12$ лет: результаты клинических исследований}

Эффективность и безопасность Ива/Лум у пациентов в возрасте $\geqslant 12$ лет с объемом форсированного выдоха за первую секунду (ОФВ 1 ) от 40 до 90\% от должного, гомозиготных по варианту гена CFTR F508del, была изучена в двух 24-недельных плацебо-контролируемых в параллельных группах исследованиях фазы III (исследование TRAFFIC и TRANSPORT) с общим количеством участников, получивших активный препарат, 1108 (549 и 559 пациентов соответственно) [20]. Дизайн исследования и методы анализа данных были идентичны для обоих исследований, за исключением применения электрокардиографии (только TRAFFIC) и фармакокинетической оценки (только TRANSPORT). Эти исследования были включены в кокрейновский систематический обзор по применению коррекTоров CFTR (с потенциаторами или без них) при патогенных вариантах гена CFTR класса II [24]. Все пациенты продолжали получать препараты базисной симптоматической терапии. Исследования продемонстрировали сопоставимую эффективность Лум 600 мг один раз в сутки и 400 мг два раза в сутки в комбинации с Ива 250 мг два раза в сутки. Выявлено умеренное, но статистически значимое $(p<0,001)$ повышение ОФВ 1 (в абсолютном исчислении на 3,3 и 2,8\% соответственно) от должного по сравнению с плацебо через 24 нед. Также в результате приема Ива/Лум отмечено статистически значимое увеличение индекса массы тела (ИМТ): на 0,28 кг/м² при Лум 600 мг один раз в сутки и 0,24 кг/м² при Лум 400 мг два раза в сутки в комбинации с Ива 250 два раза в сутки и - что, возможно, более важно - снижение частоты обострений бронхолегочного процесса на 30 и 39\% соответственно по сравнению с плацебо. Частота событий, приведших к госпитализации или использованию внутривенных антибиотиков, также была ниже в группах Ива/ Лум, чем в группе плацебо [20, 26]. Профиль безопасности Ива/Лум не отличался от такового у плацебо. Так, частота серьезных нежелательных явлений была сходной в группах плацебо и Ива/Лум. По данным объединенного анализа исследований TRAFFIC и TRANSPORT, серьезные нежелательные явления были зарегистрированы у $28,6 \%$ пациентов в группе плацебо и у 17,3-22,8\% пациентов в группах Ива/Лум. Во всех группах инфекционное обострение бронхолегочного процесса было наиболее частым серьезным нежелательным явлением (зафиксировано у 24,1\% пациентов в группе плацебо и у $13,0 \%$ пациентов в объединенной группе Ива/Лум) [20].

Долгосрочная эффективность препарата Ива/Лум была проверена в продолженном 96-недельном исследо- вании PROGRESS [21], в котором участвовали 1029 пациентов, завершивших исследования TRAFFIC и TRANSPORT. Пациентам, получавшим плацебо в последних исследованиях [20], был назначен Ива/Лум. Таким образом, общая продолжительность программы клинических исследований составила 120 нед, на протяжении которых в группе Ива/Лум значение ОФВ 1 оставалось выше исходного уровня, частота обострений бронхолегочного процесса снижалась, наблюдался стабильный рост ИМТ. На протяжении 120 нед исследований комбинированный препарат хорошо переносился и сохранял благоприятный профиль безопасности. Наиболее распространенными нежелательными явлениями были инфекционные обострения бронхолегочного процесса, кашель, увеличение количества мокроты и кровохарканье. Умеренное повышение артериального давления, которое наблюдали в исследованиях TRAFFIC и TRANSPORT, было отмечено и в исследовании PROGRESS.

По окончании исследования PROGRESS был проведен анализ данных по скорости изменения ОФВ 1 у пациентов с муковисцидозом, получавших Ива/Лум. Для оценки снижения скорости прогрессирования функции легких была сформирована контрольная группа из регистра пациентов Фонда муковисцидоза (CFFPR, США), имевшая схожие параметры тяжести заболевания и половозрастные характеристики. Сравнение показало, что годовые темпы снижения ОФВ 1 в группе Ива 250 мг плюс Лум 400 мг каждые 12 ч составили -1,33\% (95\% доверительный интервал (ДИ) - от $-1,80$ до -0,85) против -2,29\% (95\% ДИ - от $-2,56$ до -2,03) в контрольной группе [21]. Таким образом, было подтверждено положительное влияние Ива/Лум на состояние легочной функции у пациентов с муковисцидозом.

\section{Ивакафтор/лумакафтор у пациентов}

с муковисцидозом в возрасте 6-11 лет:

результаты клинических исследований

Эффективность и безопасность Ива/Лум у детей в возрасте 6-11 лет была продемонстрирована в международном 24-недельном рандомизированном плацебо-контролируемом в параллельных группах исследовании фазы III [22]. Всего в исследовании участвовало 204 пациента (103 - в группе Ива/Лум, 101 - в группе плацебо). Первичной конечной точкой было абсолютное изменение индекса легочного клиренса (ИЛК2.5) - наиболее чувствительного показателя легочной функции и структурных повреждений легких у детей [22]. Лечение препаратом Ива/Лум привело к статистически значимому снижению ИЛК2.5 и, как следствие, повышению легочной функции по сравнению с группой плацебо, средняя разница составила -1,1 (95\% ДИ - от -1,4 до -0,8). На фоне терапии Ива/Лум был продемонстрирован и рост

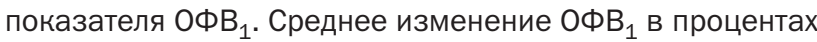
от должного для Ива/Лум по сравнению с плацебо за 24 нед составило 2,4\% (95\% ДИ - 0,4-4,4). Кроме того, прием Ива/Лум сопровождался статистически значимым увеличением ИМТ: на 24-й нед терапии средний прирост

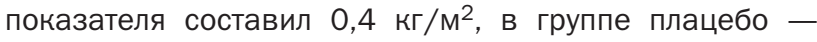
0,3 кг/м². При приеме Ива/Лум отмечено и значительное снижение концентрации хлорида натрия в потовой жидкости начиная уже с 15-х сут терапии. К 24-й нед

1 Поиск опубликованных источников выполнен в базе данных PubMed (https://pubmed.ncbi.nlm.nih.gov/), c использованием поисковых запросов в Google Scholar (https://pubmed.ncbi.nlm.nih.gov/) и в архиве журнала Journal of Cystic Fibrosis (https://www.sciencedirect.com/journal/journal-of-cystic-fibrosis) по ключевым словам "муковисцидоз", "кистозный фиброз", "ивакафтор", "лумакафтор", "CFTR модуляторы", "терапия" (и, соответственно, "cystic fibrosis", "lumacaftor", «ivacaftor", "CFTR modulators", "therapy»). Отобраны релевантные статьи, опубликованные в период с января 2014 по август 2021 г. 
разница по сравнению с группой плацебо составила $-20,8$ ммоль/л (95\% ДИ - от -23,4 до -18,2). Последнее выступает важным маркером эффективности Ива/Лум, так как известно, что высокая концентрация хлоридов в потовой жидкости является результатом нарушения транспорта ионов, обусловленного низкой активностью белка CFTR [1]. Соответственно, снижение концентрации хлорида натрия в потовой жидкости указывает на прямое влияние лекарственного препарата на активность CFTR. Ни один из препаратов симптоматической терапии не позволяет добиться такого результата [1].

Профиль безопасности Ива/Лум у детей в возрасте 6-11 лет не отличался от такового у плацебо [22]. Всего о побочных эффектах сообщили 196 (96\%) из 204 пациентов, включенных в исследование, большинство из которых были легкими - 87 (43\%) или умеренно тяжелыми - 98 (48\%). При этом частота серьезных нежелательных явлений, приведших к смерти или прекращению лечения, была сходной в группах плацебо и Ива/Лум. Серьезные нежелательные явления были зарегистрированы у 13 (13\%) из 103 пациентов в группе Ива/Лум и у $11(11 \%)$ из 101 пациента в группе плацебо. Из-за побочных эффектов лечение было прекращено у 3 (3\%) из 103 пациентов в группе Ива/Лум и у 2 (2\%) из 101 пациента в группе плацебо. Таким образом, исследование завершили 100 пациентов из основной группы.

Описанное выше исследование было продолжено (с 13 августа 2015 по 17 августа 2018 г.) как открытое расширенное, и в течение последующих 96 нед пациенты, принимавшие Ива/Лум (100 детей), продолжили терапию, пациенты из группы плацебо (96 детей) и еще дополнительно 43 ребенка (всего 239 детей) начали прием Ива/Лум (250/200 мг каждые 12 ч) [23]. Таким образом, общая продолжительность терапии Ива/Лум в исследованиях у 100 пациентов в возрасте 6-11 лет достигла 120 нед. У пациентов, продолживших лечение, среднее изменение ИЛК2.5 составило -0,85 (95\% ДИ - от -1,25 до -0,45), снижение концентрации хлоридов в потовой жидкости достигло -22,9 ммоль/л (95\% Ди - от $-25,5$ до -20,3), ИМТ увеличился на 1,78 кг/м² (95\% ДИ - от 1,56 до 1,99). Изменение качества жизни (оценка выполнена с использованием опросника CFQRDS - Cystic Fibrosis Questionnaire-Revised respiratory domain score) составило 7,4 балла (95\% ДИ от 4,8 до 10,0) [23]. У пациентов, переведенных с плацебо на Ива/Лум, среднее изменение ИЛК 2.5 составило -0,86 (95\% ДИ - от -1,33 до -0,38), снижение концентрации хлоридов в потовой жидкости - $-22,8$ ммоль/л (95\% ДИ - от $-26,3$ до -19,3), ИМТ увеличился на 2,04 кг/м² (95\% ДИ - от 1,77 до 2,31). Изменение качества жизни по CFQRDS составило 6,6 балла (95\% ДИ от 3,1 до 10,0). На протяжении 96-недельного периода Ива/Лум сохранял благоприятный профиль безопасности. ИЛК2.5 оставался ниже базового уровня в течение всего исследования. Концентрация хлоридов в потовой жидкости, сниженная в 24-недельной фазе исследования, продолжала сохраняться ниже начального уровня на протяжении всего периода исследования (120 нед), что свидетельствовало о стойком повышении активности CFTR на фоне патогенетической терапии. Увеличение ИМТ, массы тела и роста в течение столь продолжительного исследования вполне ожидаемо для детей. Вместе с тем важно отметить, что параметры ИМТ к возрасту и масса тела к возрасту, имевшие отрицательные значения до терапии, стали положительными на 96-й нед исследования, что говорит о положительном влиянии Ива/Лум на рост пациентов [23].
В исследованиях, описанных выше, у пациентов в возрасте 6-11 лет наблюдалось значительное (примерно на 20 ммоль/л) снижение концентрации хлоридов в потовой жидкости, что превышало изменения, наблюдаемые в исследовании фазы II, в котором участвовали взрослые (среднее снижение составило около 10 ммоль/л) [27]. Эти изменения были аналогичны тем, о которых сообщалось в постмаркетинговом исследовании, включавшем взрослых и детей в возрасте старше 12 лет, в котором концентрация хлорида в потовой жидкости снизилась в среднем на 17,8 ммоль/л после 8-16 нед лечения [28]. G. Connett считает, что эти исследования свидетельствуют о возможно большей эффективности Ива/Лум в отношении коррекции функции CFTR у детей по сравнению с взрослыми [26].

Интересные данные были получены в недавно завершившемся наблюдательном исследовании, в котором 160 пациентов с муковисцидозом (97 взрослых в возрасте $\geqslant 18$ лет, 43 подростка 13-17 лет и 20 детей 6-12 лет) получали Ива/Лум не менее 6 мес [29]. Анализировали ассоциацию пола, возраста, исходных значений концентрации хлоридов в потовой жидкости, ОФВ 1 , массы тела и ИМТ с изменением концентрации хлоридов в потовой жидкости в результате лечения. Была выявлена значительная разница в изменении концентрации хлоридов в потовой жидкости в ответ на лечение у пациентов разного пола (-28,6 ммоль/л у женщин против -18,0 ммоль/л у мужчин; средняя разница 10,6 ммоль/л, 95\% ДИ - 5,7-15,4). Вместе с тем отмечена слабая положительная корреляция между исходной массой тела пациентов и изменением концентрации хлоридов в потовой жидкости $(r=0,244 ; p=0,001)$, которая уменьшилась после поправки на возраст и пол, тогда как корреляция между полом и изменением концентрации хлоридов сохранялась $(r=0,253 ; p=0,001)$. Не было отмечено связи между изменением концентрации хлоридов в потовой жидкости и ОФВ 1 , а также ИМТ. Эта информация может помочь в интерпретации результатов лечения с использованием модуляторов CFTR и требует дальнейшего изучения механизмов, лежащих в основе различий в реакции на модуляторы CFTR у больных разного пола.

\section{Ивакафтор/лумакафтор у пациентов с муковисцидозом в возрасте до 6 лет: результаты клинических исследований}

Относительно недавно эффективность и безопасность препарата Ива/Лум была продемонстрирована в двух исследованиях (VX15-809-115 и VX16-809-116), последовательно проведенных в 2016-2019 гг. с участием детей с муковисцидозом в возрасте 2-5 лет [24, 30]. В первом многоцентровом открытом 24-недельном исследовании фазы III изучались безопасность, переносимость и фармакокинетика Ива/Лум [24]. Во втором многоцентровом открытом исследовании фазы III безопасность Ива/Лум изучали на протяжении 96 нед в группе детей, включенных в предыдущее исследование [30]. В общей сложности дети получали лечение в течение 120 нед от начала исследования VX15-809-115 до завершения исследования VX16-809-116. Из 60 участников, включенных в первое исследование и получавших Ива/Лум, 57 (95\%) продолжили получать исследуемый препарат на протяжении второго исследования. Исследования последовательно проводили в 20 центрах по лечению муковисцидоза в США (17 центров) и Канаде (3 центра). Дети получали Ива/Лум перорально с коррекцией дозировки на массу тела и возраст. В первом исследовании дети с муко- 
висцидозом от 2 до 5 лет включительно получали Ива в дозировке 125 мг, Лум 100 мг (при массе тела < 14 кг) или Ива 188 мг и Лум 150 мг (при массе тела $\geqslant 14$ кг) каждые 12 ч в течение 15 дней (часть А исследования для изучения безопасности и фармакокинетики). А затем продолжили до 24 нед (часть Б исследования - для оценки безопасности, фармакокинетики, фармакодинамики и эффективности). Дети могли принимать участие в частях А, Б или обеих. На момент скрининга в исследование VX16-809-116 детям с массой тела < 14 кг и в возрасте < 6 лет назначали Ива в дозировке 125 мг, Лум 100 мг; детям с массой тела $\geqslant 14$ кг и в возрасте < 6 лет - по 188 и 150 мг; детям в возрасте 6 лет и старше - по 250 и 200 мг соответственно. Во всех случаях препарат назначали каждые 12 ч.

В первом исследовании на фоне терапии отмечены снижение концентрации хлоридов в потовой жидкости на 31,7 ммоль/л, нормализация значений биомаркеров функции поджелудочной железы (концентрация фекальной эластазы 1 увеличилась, а иммунореактивного трипсиногена в сыворотке крови - снизилась), увеличение роста [24]. Препарат в целом хорошо переносился, однако в 3 (5\%) случаях из 60 Ива/Лум был отменен из-за значительного повышения активности печеночных ферментов. Наиболее распространенными нежелательными явлениями были кашель - у 38 (63\%), рвота - у 17 (28\%), пирексия - у 17 (28\%), ринорея - у 15 (25\%). Серьезные нежелательные явления были отмечены у четырех детей: в двух случаях зафиксировано обострение бронхолегочного процесса, по одному случаю - вирусный гастроэнтерит и запор.

Исследование VX16-809-116 завершили 47 (82\%) из 57 участников. У большинства - 56 (98\%) из 57 отмечено как минимум одно нежелательное явление, большая часть из которых были легкой - у 19 (33\%), или умеренной степени тяжести - у 29 (51\%). Чаще всего участники исследования отмечали появление кашля у 47 (82\%), заложенность носа - у 25 (44\%), пирексию у 23 (40\%), ринорею - у 18 (32\%), рвоту - у 17 (30\%). у 15 (26\%) участников зарегистрировано как минимум одно серьезное нежелательное явление; большинство из них типичны для муковисцидоза или детского возраста. Респираторные нежелательные явления отмечены у 5 (9\%) участников, ни одно из них не было серьезным и не привело к прекращению лечения. Повышение концентрации аминотрансфераз, в большинстве случаев легкой или средней тяжести, произошло у 10 (18\%) участников. Три (5\%) участника прекратили лечение из-за нежелательных явлений: двое - из-за повышения концентрации аминотрансфераз (у одного из них был сопутствующий панкреатит), связь с приемом исследуемого препарата была расценена как возможная; один - по причине гастрита и метаболического ацидоза (связь с приемом препарата признана маловероятной). Никаких клинически значимых отклонений или изменений в электрокардиограмме, пульсоксиметрии, в данных офтальмологического обследования и спирометрии не зафиксировано.

Положительные изменения, наблюдавшиеся в исследовании VX15-809-115, в целом сохранялись до 96-й нед исследования VX16-809-116, включая снижение концентрации хлорида в потовой жидкости. Так, изменение от исходного уровня в исследовании VX15-809-115 к 96-й нед исследования VX16-809-116 составило -29,6 ммоль/л (95\% ДИ - от -33,7 до -25,5). Отмечены стабилизация функции легких (согласно значениям ИЛК2.5) по сравнению с исходным уровнем, а также уве- личение роста и восстановление экзокринной функции поджелудочной железы у некоторых пациентов. у 4 (10\%) из 41 участника с выраженной панкреатической недостаточностью (эластаза $1<15$ мкг/г) в начале исследования VX15-809-115 определено увеличение концентрации эластазы 1 до 200 мкг/г и более на 96-й нед исследования VX16-809-116. Последнее свидетельствует о том, что функция поджелудочной железы была восстановлена в достаточной мере, чтобы можно было рассмотреть вопрос о прекращении заместительной терапии ферментами поджелудочной железы. То есть раннее применение Ива/Лум может восстановить функцию поджелудочной железы у некоторых пациентов и позволить снизить дозировку панкреатических ферментов [30].

Ожидается завершение проводимых в настоящее время исследований результатов применения Ива/Лум у детей в возрасте 1-2 лет [26]. По нашему мнению, применение этих препаратов в раннем возрасте дает больший потенциал для профилактики осложнений, связанных с муковисцидозом, и в частности развития бронхоэктазов. Снизит ли раннее применение Ива/Лум риск повреждения поджелудочной железы и развития панкреатической недостаточности у больных муковисцидозом, пока неизвестно.

\section{Влияние ивакафтора/лумакафтора}

\section{на выживаемость пациентов с муковисцидозом}

Влияние добавления Ива/Лум в дозировке 400/250 мг каждые 12 ч к симптоматической терапии на выживаемость пациентов с муковисцидозом разных возрастов в сравнении с применением только симптоматической терапии было изучено в модельном (симуляционном) исследовании [18]. Модель отслеживала динамику прогрессирования муковисцидоза и влияние на него лечения. Ключевые входные данные для моделирования были получены из рандомизированных клинических исследований фазы III (TRAFFIC, TRANSPORT, PROGRESS) [20, 21]. Было показано, что добавление Ива/Лум к симптоматической терапии приводило к наибольшему (на 23,4 года) увеличению медианы выживаемости у пациентов, начавших лечение в возрасте 6 лет, хотя значимое увеличение выживаемости, связанное с применением Ива/Лум, прогнозировалось во всех когортах, выделенных с учетом возраста начала лечения.

\section{Крупные пострегистрационные исследования}

B работе P.R. Burgel и соавт. изучались безопасность и эффективность Ива/Лум в течение первого года лечения у пациентов в возрасте $\geqslant 12$ лет (в выборке исследования было 35\% детей), которые начали принимать препарат в 2016 г. во всех 47 французских центрах муковисцидоза [31]. В это наблюдательное исследование были включены 827 пациентов (537 взрослых и 290 подростков), которых при анализе результатов лечения разделили на 3 подгруппы в зависимости от ОФВ 1 на момент начала лечения $\left(\mathrm{OФB}_{1}<40, n=121\right.$; ОФВ 1 от 40 до $89 \%, n=609 ;$ ОФВ $\left._{1} \geqslant 90, n=97\right)$. Средние возрастные характеристики по подгруппам распределялись следующим образом: 30 (от 24 до 34) лет, 21 (от 15,5 до 29) год и 20 (от 18 до 25) лет соответственно. Частота прекращения лечения в связи с нежелательными явлениями была выше у пациентов с ОФВ < 40 (28,9\%), чем у пациентов с ОФВ $140-89(16,4 \%)$ или ОФВ 1 $\geqslant 90(17,5 \%)$. У пациентов с непрерывным лечением значительное увеличение ОФВ 1 произошло в подгруппе с ОФВ $140-89(+2,9 \%$; $p<0,001)$, а также у пациентов с ОФВ $1<40(+0,5 \% ; p=0,03)$, но не 
у пациентов с ОФВ 1 $\geqslant 90(p=0,46)$. По сравнению с годом до начала лечения общая продолжительность (в сутках) внутривенной антибактериальной терапии сократилась во всех подгруппах. Также во всех подгруппах наблюдалось сопоставимое увеличение ИМТ. Таким образом, можно констатировать, что подростки и взрослые с муковисцидозом могут получить пользу от Ива/Лум независимо от исходных значений ОФВ 1 , поскольку увеличение ИМТ и сокращение продолжительности внутривенной антибактериальной терапии в течение года наблюдалось во всех подгруппах. Выводы о том, что риск побочных эффектов выше у пациентов с ОФВ $1<40$ и что у пациентов с ОФВ $1<40$ или $\geqslant 90$ повышение функции легких менее выраженное, согласуются с устоявшимся мнением о проведении набора В фазу III клинических исследований пациентов с ОФВ 40-89 [31]. Вместе с тем важно отметить, что в данном исследовании значительное увеличение ОФВ ${ }_{1}$ (> 5\%) после начала терапии модулятором CFTR было отмечено у $22 \%$ пациентов с ОФВ $1<40$ и у $27 \%$ пациентов с ОФВ $1 \geqslant 90$. Это наблюдение можно трактовать в пользу необходимости лечения с использованием Ива/Лум всех пациентов, гомозиготных по варианту F508del, независимо от исходных характеристик функции легких [31].

\section{Побочные эффекты и взаимодействие ивакафтора/лумакафтора с другими лекарственными препаратами}

Таким образом, наиболее распространенные нежелательные явления, наблюдавшиеся в клинических исследованиях фазы II и III Ива/Лум, включали кашель (21-50\%), бронхолегочное обострение (18-59\%), заложенность носа (11-20,7\%), боль в ротоглотке (6,5-20\%), головную боль $(4,8-20,7 \%)$ и одышку (13-43\%) [32]. Во время испытаний фазы III < 4\% пациентов как в группе Ива/Лум, так и в группе плацебо прекратили лечение из-за нежелательных явлений [32].

Ощущение одышки и чувства стеснения в груди можно предупредить, начав лечение с более низкой дозировки Ива/Лум [33]. Некоторые медицинские центры для взрослых с муковисцидозом начинают лечение с использованием Ива/Лум с тщательным мониторингом таких стартовых эффектов [26]. У трети больных (31\%), у которых было прекращено лечение, причиной прекращения были симптомы со стороны желудочно-кишечного тракта, такие как диарея, тошнота и боли в животе. В условиях реальной клинической практики 14\% пациентов прекратили прием препарата в течение года после начала лечения, и в двух третях случаев это было связано с побочными реакциями [34].

Ивакафтор подвергается обширному метаболизму в печени через систему цитохрома Р450/CүР3А [35]. В этой связи было высказано предположение, что повреждение печени на фоне применения этого препарата может произойти из-за токсичных или иммуногенных продуктов распада ивакафтора [35]. Лумакафтор выводится в основном в неизмененном виде с калом [36].

Пока нет убедительных свидетельств того, что Ива/ Лум вызывает клинически значимое повреждение печени. Тем не менее, рекомендуется проверять функцию печени раз в 3 мес в течение первого года лечения, а затем ежегодно. Лечение следует прервать, если активность ферментов повышается более чем в 5 раз относительно верхней границы нормы. У пациентов с предшествующим умеренным или тяжелым заболеванием печени, связанным с муковисцидозом, рекомендовано снижение дозировки препарата [21].
В клинических исследованиях было отмечено небольшое повышение артериального давления, которое наблюдалось у 0,9\% пациентов, получавших Ива/ Лум, и ни у одного пациента из группы, получавшей плацебо [20, 21].

Сообщалось о развитии катаракты у детей и подростков, получавших Ива в качестве монотерапии и при использовании в комбинации с Лум. Поэтому рекомендуется проводить базовое и ежегодное обследование глаз у детей, которым назначены эти препараты [32, 36, 37].

Учитывая, что Ива расщепляется СҮРЗА, применение препарата одновременно с сильными индукторами или ингибиторами этого фермента может повлиять на эффективность лечения за счет повышения концентрации Ива/ Лум в крови. Так, сильными ингибиторами СҮРЗА являются противогрибковые препараты, в частности итраконазол, часто используемый у пациентов с муковисцидозом. При применении таких препаратов дозировка Ива/Лум должна быть снижена. Парадоксально, но сильные индукторы СҮРЗА, такие как рифампицин и травяной сбор зверобоя, снижают эффективность Ива/Лум, поэтому следует избегать их использования [26, 32]. Еще больше усложняет лекарственное взаимодействие то, что Лум сам по себе является сильным индуктором СҮРЗА и поэтому может ограничивать эффективность препаратов, которые выводятся через этот метаболический путь. В частности, снижается эффективность гормональных контрацептивов, поэтому во избежание беременности при применении Ива/Лум следует использовать альтернативные методы контрацепции [26].

Опубликовано описание клинических случаев более тяжелого течения депрессии и тревоги после начала приема Ива/Лум [38]. Одно из возможных объяснений снижение эффективности субстратов СҮРЗА4, таких как циталопрам, эсциталопрам и сертралин, при применении Лум, который является сильным индуктором СҮРЗА4 [38]. Флуоксетин, который частично метаболизируется CYP2C9, также подвержен влиянию Лум, который является индуктором СҮР2С9. А вот пароксетин в основном является субстратом CYP2D6, на который не влияют имеющиеся в настоящее время модуляторы CFTR. Другое объяснение заключается в том, что и Лум, и Ива являются липофильными соединениями и могут пересекать гематоэнцефалический барьер, влияя на CFTR, транспорт моноаминов и рецепторы 5-НT2с в центральной нервной системе [38]. Поэтому в отношении пациентов с муковисцидозом с тревогой и депрессией до начала терапии Ива/Лум следует проводить мониторинг психического здоровья, поскольку может потребоваться корректировка дозы антидепрессантов [32, 38].

\section{Антибактериальное действие ивакафтора/ лумакафтора}

Помимо своего действия в качестве модулятора CFTR, Ива/Лум показал неожиданную синергичную активность против высокоустойчивых к полимиксину В изолятов Pseudomonas aeruginosa [39]. In vitro полимиксин В, Ива или Лум были неэффективны при индивидуальном применении против полимиксинрезистентных (минимальная ингибирующая концентрация $\geqslant 4$ мг/л) изолятов $P$. aeruginosa, полученных у пациентов с легким течением муковисцидоза. Однако при совместном применении комбинация клинически значимых концентраций полимиксина В (2 мг/л) в сочетании с Ива (8 мг/л питательной среды) или Ива (8 мг/л) + Лум (8 мг/л) проявляла синергичную высокую активность в отношении полимиксинрезистентных изоля- 
тов $P$. aeruginosa, о чем свидетельствовало 100-кратное снижение количества бактерий (KOЕ/мл) через 24 ч [39]. Комбинация Лум (отдельно) с полимиксином В показала аддитивный эффект против P. aeruginosa [39]. Маловероятно, что модуляторы CFTR могут помочь в эрадикации P. aeruginosa, однако они могут оказаться полезными в составе режимов антибактериальной терапии для минимизации риска развития бактериальных осложнений и, соответственно, прогрессирования поражения бронхолегочной системы.

\section{Влияние ивакафтора/лумакафтора}

\section{на внелегочные проявления муковисцидоза}

В нескольких исследованиях сообщалось о положительном влиянии модуляторов CFTR на массу тела и рост пациентов, на работу поджелудочной железы, желудочно-кишечного тракта и гепатобилиарной системы, на заболевания пазух носа, костей, на переносимость физических нагрузок, фертильность, психическое здоровье и иммунитет [40].

В крупном когортном исследовании с использованием данных регистра Фонда муковисцидоза (США), включавшем почти 14 тыс. пациентов (дети и взрослые), показано, что Ива/Лум и Ива ассоциировали с более высокой средней концентрацией гемоглобина в крови, причем у мужчин этот эффект был более выражен [41]. Известно, что CFTR экспрессируется в эритроцитах [42]. Однако неясно, опосредовано ли повышение гемоглобина прямым воздействием модуляторов CFTR на эритропоэз, высвобождение запасов железа или уменьшение воспаления и может ли такая терапия приводить к регрессу анемии хронического заболевания.

Еще одно потенциальное преимущество модуляторов CFTR может быть реализовано вне случаев муковисцидоза. В частности, было показано, что Ива/Лум укорачивает интервал QT на электрокардиограмме у двух пациентов с синдромом удлиненного QT типа II [43].

В исследовании А. Moheet и соавт. было показано, что Ива/Лум не влиял на секрецию инсулина или толерантность к глюкозе у пациентов с муковисцидозом, гомозиготных по F508del [44]. Вместе с тем авторы не исключали наличие умеренного влияния препарата у пациентов с уже имеющимся нарушением метаболизма глюкозы. Незначительный эффект Ива/Лум может быть связан с ограниченным воздействием на активность CFTR - ниже уровня, необходимого для восстановления CFTR-зависимой функции $\beta$-клеток [44].

\section{ЗАКЛЮЧЕНИЕ}

Терапия Ива/Лум продемонстрировала эффективность у людей с муковисцидозом разных возрастных групп. Препарат воздействует на основные факторы риска прогрессирования муковисцидоза: повышает функцию легких, снижает количество бронхолегочных обострений, в том числе требующих введения антибиотиков и госпитализаций, частично восстанавливает экзокринную функцию поджелудочной железы, увеличивает массу тела и массо-ростовой индекс, повышает качество жизни. Все это позволяет говорить о положительном влиянии Ива/Лум на течение и прогноз заболевания, в частности, согласно данным моделирования, на продолжительность жизни пациентов с муковисцидозом, гомозиготных по мутации F508del.

\section{ИСТОЧНИК ФИНАНСИРОВАНИЯ}

Не указан.

\section{FINANCING SOURCE}

Not specified.

\section{РАСКРЫТИЕ ИНТЕРЕСОВ}

Н.Ю. Каширская - получение гонорара за научнопедагогическую деятельность: "Санофи", "Фармаксис", "Генериум", "Эбботт".

P.A. Зинченко - получение гонорара за научно-педагогическую деятельность: "Новартис».

Н.В. Петрова подтвердила отсутствие конфликта интересов, о котором необходимо сообщить.

\section{DISCLOSURE OF INTEREST}

Nataliya Yu. Kashirskaya - receives fees for educational and research activity from Sanofi, Pharmaxis, Generium, Abbott.

Rena A. Zinchenko - receives fees for educational and research activity from Novartis.

Nika V. Petrova confirmed the absence of a reportable conflict of interests.

\section{ORCID}

H.Ю. Каширская

https://orcid.org/0000-0003-0503-6371

Н.В. Петрова

https://orcid.org/0000-0001-5933-6594

P.A. Зинченко

https://orcid.org/0000-0003-3586-3458

\section{СПИСОК ЛИТЕРАТУРЫ / REFERENCES}

1. Муковисцидоз / под ред. Н.Ю. Каширской, Н.И. Капранова, Е.И. Кондратьевой. 2-е изд., перераб. и доп. - М.: ИД "МЕДПРАКТИКА-М»; 2021. - 680 с. [Mukovistsidoz. Kashirskaya NYu, Kapranov NI, Kondrat'eva El, ed. 2nd ed., revised and expanded. Moscow: Publishing House “MEDPRACTIKA-M"; 2021. 680 p. (In Russ).]

2. Mishra A, Greaves R, Massie J. The relevance of sweat testing for the diagnosis of cystic fibrosis in the genomic era. Clin Biochem Rev. 2005;26(4):135-153.

3. Jentsch TJ, Maritzen T, Zdebik AA. Chloride channel diseases resulting from impaired transepithelial transport or vesicular function. J Clin Invest. 2005;115(8):2039-2046. doi: 10.1172/ $\mathrm{JCl} 25470$

4. Kogan I, Ramjeesingh M, Li C, et al. CFTR directly mediates nucleotide-regulated glutathione flux. EMBO J. 2003;22(9): 1981-1989. doi: 10.1093/emboj/cdg194
5. Cystic Fibrosis Mutation Database. Available online: http://www.genet.sickkids.on.ca. Accessed on September 9, 2021. 6. Zielenski J. Genotype and phenotype in cystic fibrosis. Respiration. 2000;67(2):117-133. doi: 10.1159/000029497

7. Dechecchi MC, Tamanini A, Cabrini G. Molecular basis of cystic fibrosis: from bench to bedside. Ann Transl Med. 2018;6(17):334. doi: $10.21037 /$ atm.2018.06.48

8. De Boeck K, Vermeulen F, Dupont L. The diagnosis of cystic fibrosis. Presse Medicale. 2017;46(6 Pt 2):e97-e108. doi: 10.1016/j.Ipm.2017.04.010

9. Zaher A, ElSaygh J, Elsori D, et al. A Review of Trikafta: Triple Cystic Fibrosis Transmembrane Conductance Regulator (CFTR) Modulator Therapy. Cureus. 2021;13(7):e16144. doi: 10.7759/ cureus.16144

10. Регистр больных муковисцидозом в Российской Федерации. 2019 год / под редакцией Н.Ю. Каширской, Е.И Кондратьевой, 
С.А. Красовского и др. - М.: ИД "МЕДПРАКТИКА-М»; 2021. 68 c. [Registr bol'nykh mukovistsidozom v Rossiiskoi Federatsii. 2019 god. Kashirskaya NYu, Kondratieva El, Krasovsky SA, eds., et al. Moscow: Publishing House "MEDPRACTIKA-M"; 2021. 68 p. (In Russ).]

11. Veit G, Avramescu RG, Chiang AN, et al. From CFTR biology toward combinatorial pharmacotherapy: expanded classification of cystic fibrosis mutations. Mol Biol Cell. 2016;27(3):424-433. doi: 10.1091/mbc.E14-04-0935

12. De Boeck K, Zolin A, Cuppens $\mathrm{H}$, et al. The relative frequency of CFTR mutation classes in European patients with cystic fibrosis. J Cyst Fibros. 2014;13(4):403-409. doi: 10.1016/j.jcf.2013.12.003 13. Кондратьева Е.И., Амелина Е.Л., Чернуха М.Ю. и др. Обзор клинических рекомендаций "Кистозный фиброз (муковисцидоз)" (2020) // Пульмонология. 2021;31(2):135-146. [Kondratyeva El, Amelina EL, Chernukha MYu, et al. Review of clinical guidelines “Cystic fibrosis", 2020. Pulmonologiya. 2021;31(2):135-146. (In Russ).] doi: 10.18093/0869-0189-2021-31-2-135-146 14. Van Goor F, Straley KS, Cao D, et al. Rescue of DeltaF508CFTR trafficking and gating in human cystic fibrosis airway primary cultures by small molecules. Am J Physiol Lung Cell Mol Physiol. 2006;290(6):L1117-L1130. doi: 10.1152/ajplung.00169.2005 15. Kalydeco ${ }^{\circledR}$ (ivacaftor) Tablets Label. Available online: https://www.accessdata.fda.gov/drugsatfda_docs/label/2017/ 203188s022l_207925s003lbl.pdf. Accessed on January 15, 2021. 16. Flume PA, Van Devanter DR. State of progress in treating cystic fibrosis respiratory disease. BMC Med. 2012;10:88. doi: 10.1186/1741-7015-10-88

17. Van Goor F, Hadida S, Grootenhuis PDJ, et al. Correction of the F508del-CFTR protein processing defect in vitro by the investigational drug VX-809. Proc Natl Acad Sci U S A. 2011;108(46): 18843-18848. doi: 10.1073/pnas.1105787108

18. Rubin JL, O'Callaghan L, Pelligra C, et al. Modeling longterm health outcomes of patients with cystic fibrosis homozygous for F508del-CFTR treated with lumacaftor/ivacaftor. Ther Adv Respir Dis. 2019;13:1753466618820186. doi: $10.1177 / 1753466618820186$

19. Wang XR, Li C. Decoding F508del misfolding in cystic fibrosis. Biomolecules. 2014;4(2):498-509. doi: 10.3390/biom4020498

20. Wainwright CE, Elborn JS, Ramsey BW, et al. LumacaftorIvacaftor in Patients with Cystic Fibrosis Homozygous for Phe508del CFTR. N Engl J Med. 2015;373(3):220-231. doi: 10.1056/ NEJMoa1409547

21. Konstan MW, McKone EF, Moss RB, et al. Assessment of safety and efficacy of long-term treatment with combination lumacaftor and ivacaftor therapy in patients with cystic fibrosis homozygous for the F508del-CFTR mutation (PROGRESS): a phase 3, extension study. Lancet Respir Med. 2017;5(2):107-118. doi: 10.1016/ S2213-2600(16)30427-1

22. Ratjen F, Hug C, Marigowda G, et al. VX14-809-109 investigator group. Efficacy and safety of lumacaftor and ivacaftor in patients aged 6-11 years with cystic fibrosis homozygous for F508del-CFTR: a randomised, placebo-controlled phase 3 trial. Lancet Respir Med. 2017;5(7):557-567. doi: 10.1016/S2213-2600(17)30215-1

23. Chilvers MA, Davies JC, Milla C, et al. Long-term safety and efficacy of lumacaftor-ivacaftor therapy in children aged 6-11 years with cystic fibrosis homozygous for the F508del-CFTR mutation: a phase 3, open-label, extension study. Lancet Respir Med. 2021;9(7):721-732. doi: 10.1016/S2213-2600(20)30517-8

24. McNamara JJ, McColley SA, Marigowda G, et al. Safety, pharmacokinetics, and pharmacodynamics of lumacaftor and ivacaftor combination therapy in children aged 2-5 years with cystic fibrosis homozygous for F508del-CFTR: an open-label phase 3 study. Lancet Respir Med. 2019;7(4):325-335. doi: 10.1016/ S2213-2600(18)30460-0

25. Southern KW, Murphy J, Sinha IP, Nevitt SJ. Corrector therapies (with or without potentiators) for people with cystic fibrosis with class II CFTR gene variants (most commonly F508del). Cochrane Database Syst Rev. 2020;12(12):CD010966. doi: 10.1002/14651858. CD010966.pub3

26. Connett GJ. Lumacaftor-ivacaftor in the treatment of cystic fibrosis: design, development and place in therapy. Drug Des Devel Ther. 2019;13:2405-2412. doi: 10.2147/DDDT.S153719

27. Boyle MP, Bell SC, Konstan MW, et al. A CFTR corrector (lumacaftor) and a CFTR potentiator (ivacaftor) for treatment of patients with cystic fibrosis who have a phe508del CFTR mutation: a phase 2 randomised controlled trial. Lancet Respir Med. 2014;2(7):527-538. doi: 10.1016/S2213-2600(14)70132-8

28. Graeber SY, Dopfer C, Naehrlich L, et al. Effects of lumacaftor ivacaftor therapy on cystic fibrosis transmembrane conductance regulator function in Phe508del homozygous patients with cystic fibrosis. Am J Respir Crit Care Med. 2018;197(11):1433-1442. doi: 10.1164/rccm.201710-19830C

29. Aalbers BL, Hofland RW, Bronsveld I, et al. Females with cystic fibrosis have a larger decrease in sweat chloride in response to lumacaftor/ivacaftor compared to males. J Cyst Fibros. 2021; 20(1):e7-e11. doi: 10.1016/j.jcf.2020.05.004

30. Hoppe JE, Chilvers M, Ratjen F, et al. Long-term safety of lumacaftor-ivacaftor in children aged 2-5 years with cystic fibrosis homozygous for the F508del-CFTR mutation: a multicentre, phase 3, open-label, extension study. Lancet Respir Med. 2021;9(9): 977-988. doi: 10.1016/S2213-2600(21)00069-2

31. Burgel PR, Durieu I, Chiron R, et al. French Cystic Fibrosis Reference Network study group. Clinical response to lumacaftorivacaftor in patients with cystic fibrosis according to baseline lung function. J Cyst Fibros. 2021;20(2):220-227. doi: 10.1016/ j.jcf.2020.06.012

32. Gavioli EM, Guardado N, Haniff F, et al. A current review of the safety of cystic fibrosis transmembrane conductance regulator modulators. J Clin Pharm Ther. 2021;46(2):286-294. doi: 10.1111/ jcpt.13329

33. Taylor-Cousar JL, Jain M, Barto TL, et al. Lumacaftor/ivacaftor in patients with cystic fibrosis and advanced lung disease homozygous for F508del-CFTR. J Cyst Fibros. 2018;17(2):228-235. doi: 10.1016/j.jcf.2017.09.012

34. Brokaar E, van Leeuwen M, Leegwater E, et al. Adverse drug reactions and discontinuation rate during the first year on orkambi - the earliest results of the STORM study. J Cyst Fibros. 2019;18(Suppl 1):S130. doi: 10.1016/S1569-1993(19)30553-3 35. Whiting P, Al M, Burgers $L$, et al. Ivacaftor for the treatment of patients with cystic fibrosis and the G551D mutation: a systematic review and cost-effectiveness analysis. Health Technol Assess. 2014;18(18):1-106. doi: 10.3310/hta18180

36. Talamo Guevara M, McColley SA. The safety of lumacaftor and ivacaftor for the treatment of cystic fibrosis. Expert Opin Drug Saf. 2017;16(11):1305-1311. doi: 10.1080/ 14740338.2017.1372419

37. McColley SA. A safety evaluation of ivacaftor for the treatment of cystic fibrosis. Expert Opin Drug Saf. 2016;15(5):709-715. doi: 10.1517/14740338.2016.1165666

38. Talwalkar JS, Koff JL, Lee HB, et al. Cystic fibrosis transmembrane regulator modulators: implications for the management of depression and anxiety in cystic fibrosis. Psychosomatics. 2017;58(4): 343-354. doi: 10.1016/j.psym.2017.04.001

39. Schneider EK, Azad MA, Han ML, et al. An unlikely pair: the antimicrobial synergy of polymyxin $b$ in combination with the cystic fibrosis transmembrane conductance regulator drugs KALYDECO and ORKAMBI. ACS Infect Dis. 2016;2(7):478-488. doi: 10.1021/ acsinfecdis.6b00082

40. Sergeev V, Chou FY, Lam GY, et al. The Extrapulmonary Effects of Cystic Fibrosis Transmembrane Conductance Regulator Modulators in Cystic Fibrosis. Ann Am Thorac Soc. 2020;17(2):147-154. doi: 10.1513/AnnalsATS.201909-671CME

41. Gifford AH, Heltshe SL, Goss CH. CFTR modulator use is associated with higher hemoglobin levels in individuals with cystic fibrosis. Ann Am Thorac Soc. 2019;16:331-340. doi: 10.1513/ AnnalsATS.201807-4490C

42. Schwartz PJ, Gnecchi M, Dagradi F, et al. From patient-specific induced pluripotent stem cells to clinical translation in long QT syndrome type 2. Eur Heart J. 2019;40(23):1832-1836. doi: 10.1093/eurheartj/ehz023

43. Ebner A, Nikova D, Lange T, et al. Determination of CFTR densities in erythrocyte plasma membranes using recognition imaging. Nanotechnology. 2008;19:384017. doi: 10.1088/ 0957-4484/19/38/384017

44. Moheet A, Beisang D, Zhang L, et al. PROSPECT Investigators of the Cystic Fibrosis Foundation Therapeutics Development Network. Lumacaftor/ivacaftor therapy fails to increase insulin secretion in F508del/F508del CF patients. J Cyst Fibros. 2021;20(2):333-338. doi: 10.1016/j.jcf.2020.09.001 